\title{
Technological Advances and the Changing Nature of Work: Deriving a Future Skills Set
}

\author{
Yasmin Danuser, Michael J. Kendzia* \\ ZHAW, Winterthur, Switzerland \\ Email: *kend@zhaw.ch
}

How to cite this paper: Danuser, Y., \& Kendzia, M. J. (2019). Technological Advances and the Changing Nature of Work: Deriving a Future Skills Set. Advances in Applied Sociology, 9, 463-477. https://doi.org/10.4236/aasoci.2019.910034

Received: July 2, 2019

Accepted: October 7, 2019

Published: October 10, 2019

Copyright $\odot 2019$ by author(s) and Scientific Research Publishing Inc. This work is licensed under the Creative Commons Attribution International License (CC BY 4.0).

http://creativecommons.org/licenses/by/4.0/

\begin{abstract}
Technological advances in the field of artificial intelligence, machine learning and robotics are highly likely to change the nature of work for individuals in the developed world. In line with that, the latest research points to the important role of socio-emotional or soft skills. Investing in these skills enhances the individual's labor market productivity. Accordingly, the paper seeks to develop an adequate skill set to meet future demands at the workplace. The results reveal four main areas to play a significant role in the future workforce. This holds in particular for areas of human-machine collaboration, where both parties are allowed to demonstrate their comparative advantages.
\end{abstract}

\section{Keywords}

Destruction Effect, Capitalization Effect, Soft Skills

\section{Introduction}

Whenever the impact of technological advances on work has been discussed, fear has been created in the form of the end of work or the possible disappearance of work (Brynjolfsson \& McAfee, 2016; Wilson, 1996; Rifkin, 1995). Although technology can be considered as the main source of economic progress, it has generated cultural anxiety throughout history (Mokyr et al., 2015).

However, core human competences are less replaceable through machines, especially in areas such as high productivity occupations, which depend on specific skills and experiences. This holds true for occupations to be associated with human skills that are complementary to technological possibilities (Eichhorst, 2017).

While Katz and Murphy (1992) point to the impact of technological change on labor earnings, the latest research (Verick, 2018) sheds more light on the shifting skill set through technological change. Accordingly, access to technology tends to enhance productivity and working environments. 
That said, it is likely that the skill set, enabling individuals to compete in the future labor market, will be changing over time. Following this argumentation, a more complementary skill set will be needed, ranging from literacy and numeracy skills to the right socio-emotional skill set needed to work collaboratively and flexibly (OECD, 2016).

In this context, research frequently points to the importance of socio-emotional or soft skills (Larsen et al., 2016; De Carvalho \& Rabechini, 2015, Syed et al., 2010). Hence, the paper seeks to contribute to developing a soft skill set promoting the individual's labor market success in times of changing demands at the workplace.

\section{Theoretical Evidence}

\section{Defining socio-emotional or soft skills}

Whereas some soft skills may be rooted on inborn talent, it appears likely that many skills may be acquired and changed through a variety of experiences in life (Wickramasinghe \& Perera, 2010). In some instances, the terms employability skills or enterprise skills are used, indicating that they are transferable between industries and occupations (Deloitte, 2017).

A further challenge in the definition of soft skills may be that they are not only associated with skills but also with values, beliefs, dispositions, traits, and behaviors (Matteson et al., 2016). Finally, the understanding of what soft skills are varies widely and the perception differs from context to context (Schulz, 2008).

In this work, the term soft skills refer to general, transferable and malleable skills. By synthesizing the existing literature in the respective field, Andrews \& Higson (2008) lay down general, transferable, and malleable skills as follows:

- Professionalism \& reliability

- The ability to work under pressure

- The ability to plan and think strategically

- The capability to communicate and interact with others, either in teams or through networking

- Good written and verbal communication skills

- Information and communication technology skills

- Creativity and self-confidence

- Good self-management and time-management skills

- A willingness to learn and accept responsibility

Note: The authors refer to Elias \& Purcell, 2004; Nabi, 2003; Tucker et al., 2000; McLarty, 1998.

Accordingly, they are not specific to any occupation and may be used in various situations under different circumstances. Following this approach, skills are subject to change during the individual's lifetime and amplify the human comparative advantage over machines. 
Defining artificial intelligence, machine learning, robotics, augmented and virtual reality

Besides the phenomenon such as artificial intelligence (AI), machine learning (ML), and robotics, the term big data refers to large data sets being analyzed by computers in order to reveal certain patterns, trends, and other associations. Big data and analytics can be interpreted by collecting as well as the evaluating data from different sources, equipment as well as systems (Larsen et al., 2016).

ML is used to describe the field of computer science, which deals with algorithms that learn from and are able to make predictions on data without needing to be programmed explicitly. Hence, ML forms an important basis for AI technologies (Wilson \& Daugherty, 2018). Engineers may be able to program a machine to master tasks autonomously by examining successful examples of the task conducted by others (Autor, 2015).

Most recent advances in ML refer to the Artificial Neural Network (ANN), a powerful computing system to handle difficult as well as challenging problems, inspired by the human nervous system (Zhang, 2018). A further area, where rapid recent acceleration in digital improvement can be seen, is robotics (Brynjolfsson \& McAfee, 2016).

Moreover, the future of work is assumed to be increasingly impacted by virtual reality (VR), allowing individuals to immerse themselves into multisensorial, three-dimensional, 360-degree computer-simulated environments as well as to interact with others in these environment (Schwab \& Davis, 2018).

One form of VR is augmented reality (AR), further enhancing the user's perception of the reality. AR can provide visible information about the real world, increasing the interactivity of physical spaces and object, which can be exemplified by the use of Google Glasses or the Microsoft HoloLens (Schwab \& Davis, 2018).

\section{Labor market polarization}

Another phenomenon occuring on the labor market constitutes labor market polarization, describing the increasing employment in the high-skill and in the low-skill occupations as well as slower growth in middle-skill jobs (Goos et al., 2011). This phenomenon can be observed mainly in Anglo-Saxon and European economies (Larsen et al., 2016).

According to the Routinization Hypothesis, routine tasks are more likely to be substituted since machines are much better than humans at performing routine, codifiable tasks, corresponding to an explicit set of rules (Deming, 2017). Autor \& Dorn (2013) expect a structural shift from middle-income manufacturing to low-income service operations.

Autor (2015) argues that human capital investment should aim at producing skills that are complemented, rather than substituted by technology. It appears that the polarization effect leads to growth for both manual routine tasks found in low-skill jobs as well as high-skill cognitive/abstract tasks (high-skill jobs), while the routine tasks found in middle-skill occupations are hollowed out. 
This phenomenon might be supported by the Theory of Mind, indicating that human interaction is based on empathy (Camerer et al., 2005). That is, cognitive abilities infer mental states, such as intentions and beliefs of others through processing their physical appearance and overt behavior (Ondobaka et al., 2017). Thus, Frey \& Osborne (2013) argue that tasks requiring social skills constitute a key bottleneck to computerization.

\section{Methodological Approach}

As illustrated by Figure 1, the destruction effect describes the substitution of labor (Schwab, 2017) because of automation or other labor-saving technologies (WTO, 2017). Technology-fueled disruptions may substitute capital for labor, which forces workers to become unemployed or to re-allocate their skills (Schwab, 2017, Appendix B).

On the other hand, it can be considered that technological progress is labor-augmenting. That is, technology may also contribute to significant job growth. This phenomenon can be described by the capitalization effect. In this case, workers are complemented by improved technology, leading to higher productivity and increased income. As a result, new businesses, occupations and even new industries may occur (Schwab, 2017).

Referring to past developments and both effects, however, only little effects on employment have been observable so far. At the beginning of the $19^{\text {th }}$ century, 90 percent of the working population in the US was employed in the agricultural sector. Today, professions in agriculture account only for less than two percent. This shift has been taking place rather smoothly from a societal point of view, without significant social disruption or unemployment on a massive scale (Schwab, 2017).

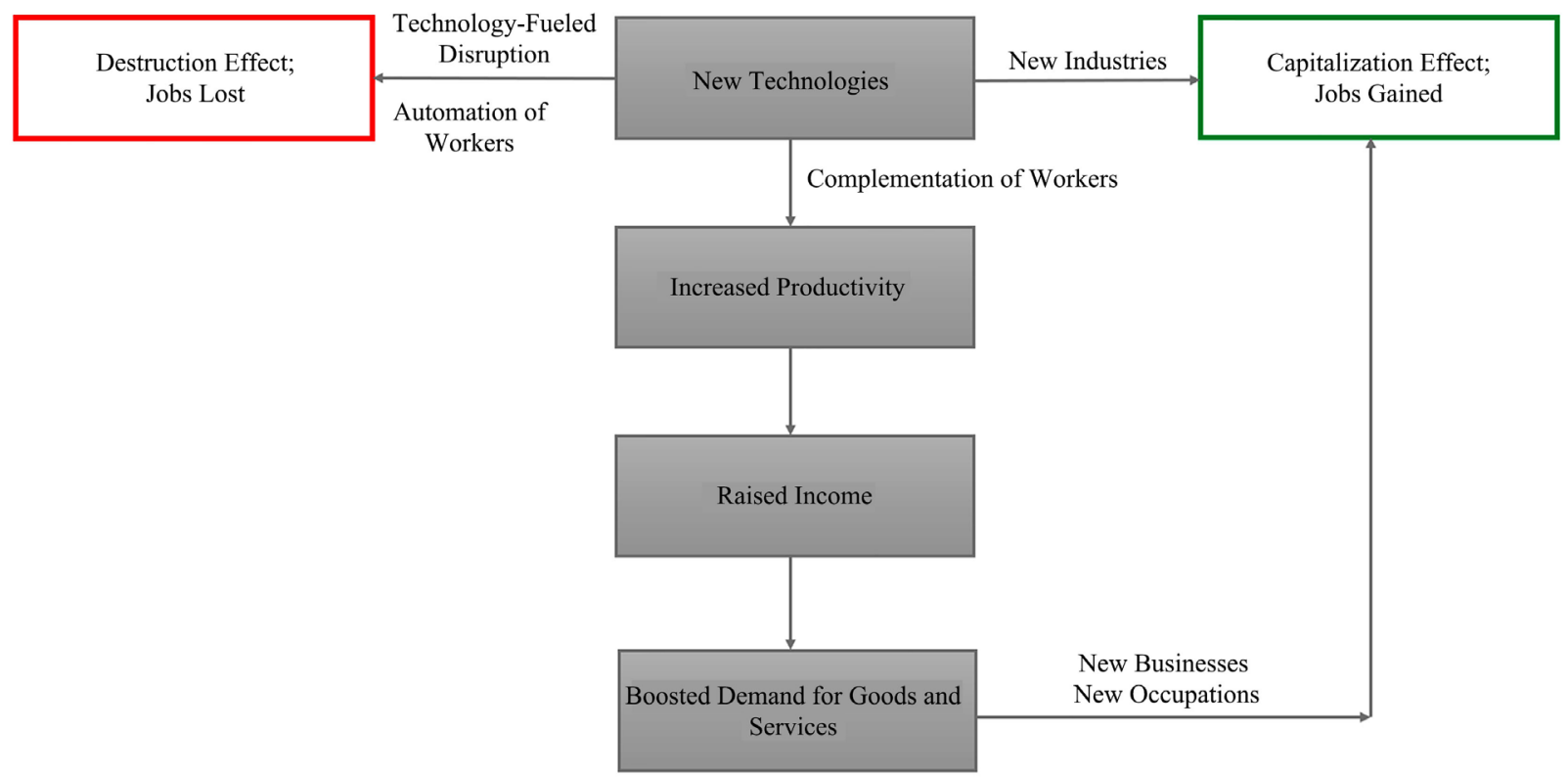

Figure 1. Designing the destruction and capitalization effect. Source: Own representation based on Schwab (2017) and Colvin (2015). 
The Routinization Hypothesis provides evidence that industries in which routine tasks were applied heavily have been most significantly disrupted by the destruction effect (Goos et al., 2009). Routine tasks can be characterized as precise, well-understood procedures, which can be, and increasingly are, codified in computer software and performed by machines. Routine tasks may be divided into routine cognitive tasks as well as routine manual tasks. Routine cognitive tasks typically refer to middle-skill work such as clerical, administrative, and sales occupations (Acemoglu \& Autor, 2011).

In contrast, routine manual tasks can be found in production and operative occupations in low-skilled jobs, including repetitive production and monitoring jobs (Acemoglu \& Autor, 2011).

Routine manual tasks can be characteristics by food preparation and serving jobs, cleaning as well as janitorial work, grounds cleaning and maintenance, in-person health assistance by home help aids as well as numerous jobs in security and protective services (Autor, 2015).

Routine tasks are highly susceptible to computerization. Those tasks can be further differentiated into non-routine cognitive/abstract tasks and non-routine manual tasks. Non-routine cognitive/abstract tasks refer to high-skill occupations such as managerial, professional and technical work (Acemoglu \& Autor, 2011), flexibility, and judgment (Deming, 2017).

Non-routine manual tasks can be found in service occupations and are less likely to be substituted than routine tasks but more susceptible to automation than non-routine cognitive/abstract tasks, since they typically require a high degree of flexibility, physical adaptability (Frey \& Osborne, 2013), visual and language recognition as well as interpersonal interaction (Autor, 2015).

It appears that the present technological change decreases the demand for routine tasks (WTO, 2017) encompassing routine manual tasks as well as routine cognitive/abstract (Acemoglu \& Autor, 2011), as illustrated by Figure 2.

The investigation is based on empirical research, where personal interviews have been conducted with a row of experts in the field of technological development. Appendix A summarizes the sample of these specialists from companies located in Switzerland. Global innovation is driven by high-income economies. Switzerland has been ranking first in the Global Innovation Index since 2011 (Cornell University, INSEAD, \& WIPO, 2018) and can be considered as one of the most advanced economies (UNDP, 2018).

Additionally, the analysis focused on specialists in areas such as technology and future workplaces in Switzerland. In this context, many of the interviewees represent prominent internationally operating companies. Given their seniority in the company, for example, founder, $\mathrm{CEO}$, CTO, and other leading managing positions, the interviewees represent expert knowledge in the area of future skills. 


\section{Findings}

\section{The substitution of certain jobs constitutes rather a gradual process}

Currently, a gap between technological possibilities and their later implementation exists. This may also hold true for robot substitution. In theory, technology may destruct industries at a fast pace. Nevertheless, whether technology will have this immediate impact on the real working world is highly questionable.

Many jobs may exist for much longer than they needed to persist given the technological advances. The latter allow for a better use of brain power, which in turn might have a positive impact concerning the individuals' motivation. This scenario highlights a positive human-machine interaction, where both comparative advantages are amplified.

AI may be a tool to allow workers to focus on the qualities unique to human beings. Despite its substitutional effect, technical advances can also be regarded as a supporting tool for human labor. Given that $\mathrm{AI}$ is not tangible, and thus appears to be abstract, it can also be seen as a way to facilitate the qualities of a human worker.
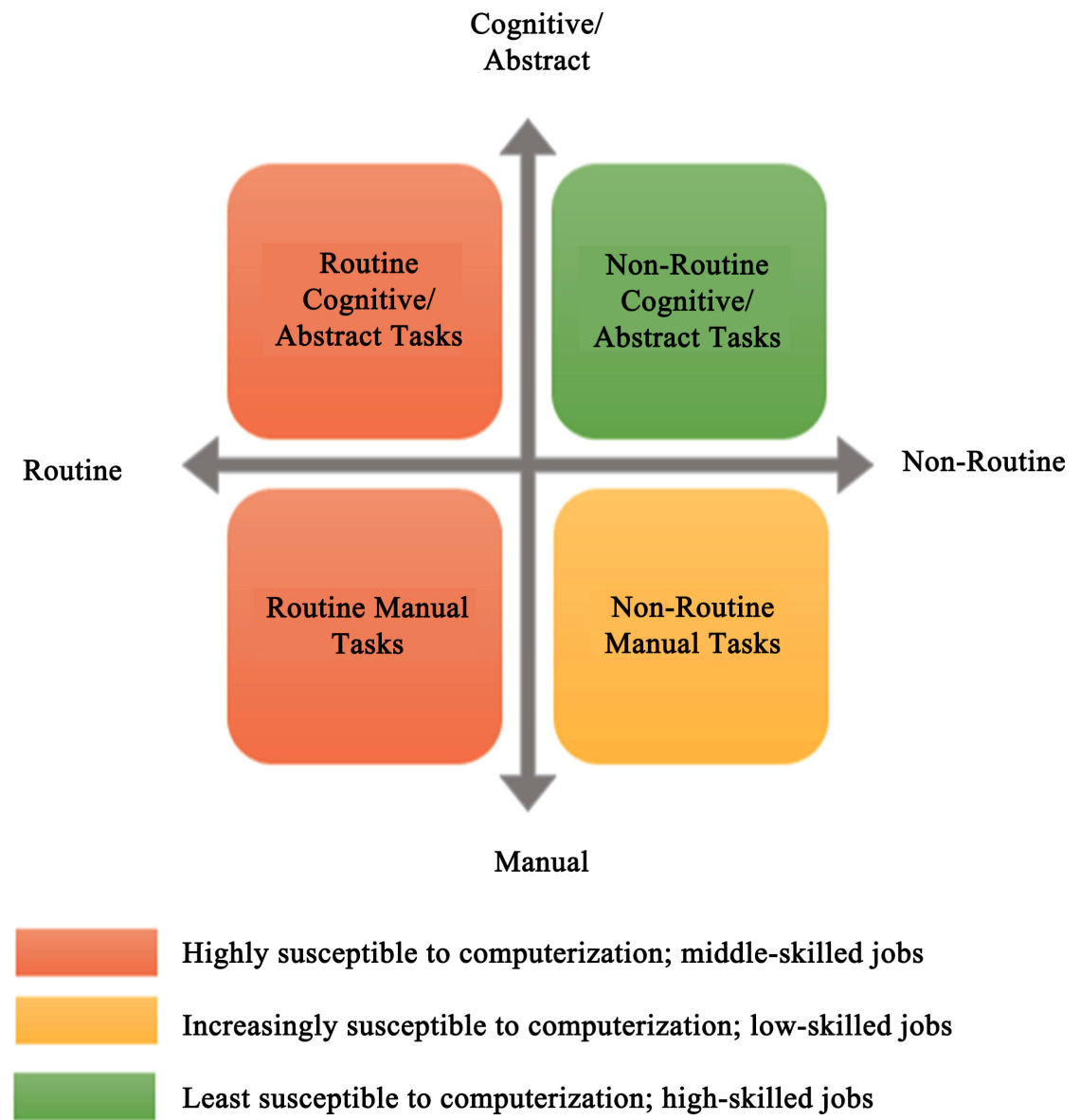

Highly susceptible to computerization; middle-skilled jobs Increasingly susceptible to computerization; low-skilled jobs Least susceptible to computerization; high-skilled jobs

Figure 2. Impact of automation on certain tasks. Source: Own representation based on Autor et al. (2003), Acemoglu \& Autor (2011), and Frey \& Osborne (2013). 


\section{Undisputed advantages of computers regarding data processing}

The advantage of the capability of machines for a human brain is able to efficiently compare a high number of X-ray images and at the same time scan them for common patterns. Within this area, it is undisputed that the capabilities of machines clearly surpass those of humans. Regarding AI, the three variables of speed, volume, and complexity mark a comparative advantage of machines, since a human brain is limited in the cognitive capacity, due to biological reasons.

Until recently, data processing was largely attributed to the human comparative advantage. Today, data processing is carried out by machines in a very broad range of areas. Even gut feeling may appear as a multitude of information that humans form to a sentiment or opinion.

Recent advancements in AI imply a shift in a skill set necessary to compete in the labor market. Robotics is able to change jobs in the field of craft industry through substitution. Likewise, AI might also cause similar developments in the more cognitive field, in more numbers-driven and fact-based occupations as seen in accounting or in legal professions. Therefore, it is likely that in many occupations different skills will be required.

\section{The focus of work itself is likely to shift}

Today's skills focus mainly on execution and implementation. This might move towards a skill set allowing for more non-linear work and social interaction. Creative, collaborative work as well as the communication of results is expected to become more relevant than physical or cognitive work. Hence, the need for cognitive, analytic as well as algorithmic thinking will be emerging in many roles.

Translating the human world into the machine world gains in importance next to the field of soft skills such as empathy and creativity. Specific in-depth knowledge in a domain remains still important. In this context, referring to the theory which employs the vertical bar of the $\mathrm{T}$ as the in-depth of expertise and the horizontal bar constituting the ability to collaborate across different fields.

The term cross-disciplinary competences might be used in order to emphasize their importance. When considering the baby boomer generation, that is currently exiting the working world, it appears that this generation paid less attention to the importance of soft skills. With that generation retiring, a change in valuation is likely to occur.

\section{Change handling skills deem necessary}

The future of work seems to be increasingly difficult for individuals, who have a hard time adapting to new situations. It is assumed that the demand for the skill of personal adaptability is likely to increase. Simultaneously, cognitive skills are an important contributor to adaptability.

Cognitive abilities go in line with the successful adaptation of new situations. However, adaptability depends on personality traits, such as openness for change and the perception of chances and risks. The willingness to continuously gain the knowledge necessary and to be able to grow alongside the technological advances is essential for the future of work. 
Personal adaptability, flexibility as well as the openness to change, is likely to ameliorate success at the workplace, since there is no guarantee that one's current occupation will still exist (at all or in the same form) five or ten years from now. Adaptability can be attributed to major changes such as a professional reorientation, whereas flexibility describes one's ability to deal with small alternations in one's daily working life.

\section{Acquiring skills for continuous improvement}

Lifelong learning skills refer to the willingness to continuously update the individuals' own skill set. For this to happen, enthusiasm is essential, as there is a mutual dependency between enthusiasm and lifelong learning. Both phenomena shall be complemented by curiosity, referring to the interest and openness towards the unfamiliar. That said, all three skills build the basis for the skills for continuous improvement.

In times of both more virtual and intercultural teams, the need for empathic behavior is likely to grow. Yet, empathy is hidden behind skills such as communication. Nonetheless, the ability to empathize can hardly be replaced and might become increasingly valuable. In general, individuals tend to be treated by a real person, equipped with the necessary skills to emphasize.

One day there might exist nursing-robots, helping the elderly to wash their hands in the morning and to brush their teeth. However, even though the robots will be able to capture facial expressions, it will be hard for them to tell when a person needs comforting. When a gaze is empty, it is difficult to assess whether it is due to Alzheimer's disease or simply a person being tired. These subtle differences are hardly distinguishable and thus a replication via an algorithm proves to be extremely difficult.

Leadership as the ability to share a vision through communication

Communication in the sense of gathering and transmitting information, whether structured or unstructured, is deemed an even more necessary skill for the future. The need for communication is likely to intensify, as it is crucial to be as transparent as possible and to clearly explain envisioned changes within a company.

Additionally, the skills to communicate the value proposition of a product to a client and to have a meaningful conversation remain equally important. In the past, workers from older generations were less confronted with sharing information in a team, as more focus was placed on the individual results, instead of the ultimate outcome of a team. Thus, a shift in paradigm towards an increased importance of teamwork is visible. This implies a new paradigm away from the classical linear and hierarchic functions to increasingly flat hierarchies.

At the same time, collaboration between individuals from different cultural and educational backgrounds becomes more common. Individuals, who understand these mechanisms, will most certainly be privileged. Evidence for this development can be observed by the growing interdependence of organizations within these cross-company ecosystems, which, in turn, is a result of the intensification of complexity. 


\section{Out-of-the-box thinking skills foster the creative process}

Creativity constitutes another relevant skill in the future, as displayed in Figure 3. Nevertheless, the concept of creativity remains relatively unclear. Creativity may be regarded as a means to problem solving. Creativity broken down is only the result of logic reasoning-something that can also be called intuition. However, intuition may be the consequence of experience that might unconsciously be reflected in a piece of art.

When referring to creativity solely as applying something in a different context, then creativity may not be a key skill in the future, since computers will be able to substitute for this task. However, when referring to creativity as a fluid concept that cannot be traced back to a pure data processing mechanism, this might constitute an important skill for employees. Creativity, in the sense of out-of-the-box thinking, in order to escape the borders of the norms and their structures will be crucial.

In contrast, critical thinking refers to challenging an existing process and to question, whether a routine is still valid, or a task needs to be adapted. Critical thinking should be more positively formulated by using the terms "thinking out-of-the-box" or "looking for new ways". Challenging existing processes, being open for change, or becoming an early-mover in the market are vital in view of future requirements.

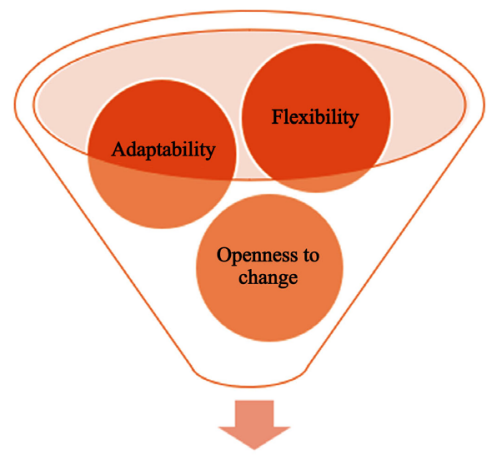

Change Handling Skills

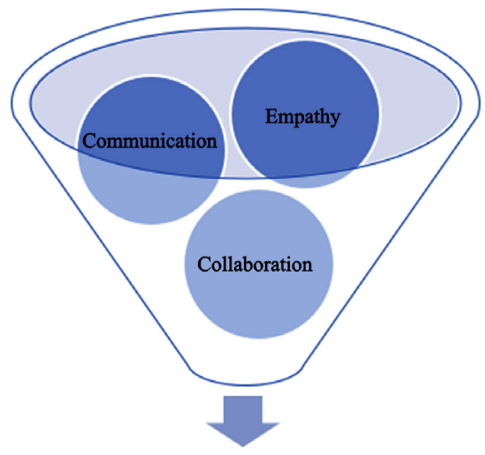

Interaction Skills

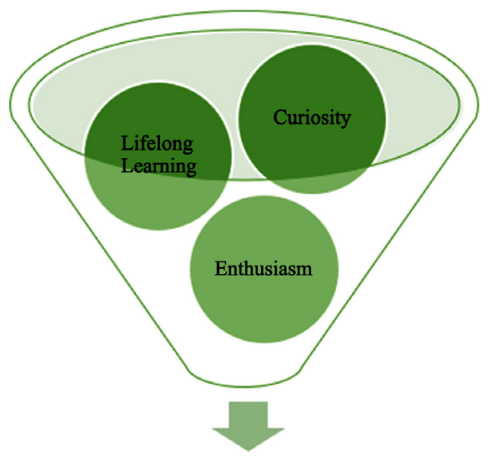

Skills for Continuous Improvement

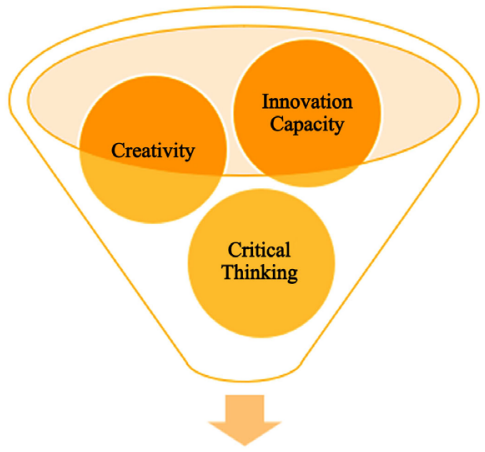
Out-of-the-Box Thinking
Skills

Figure 3. Development of a skills cluster. Source: Own creation based on the generated and categorized findings. 


\section{Discussion of Findings}

There is a considerable amount of uncertainty, as always when making predictions for the future. This holds particularly true for abstract and intangible concepts such as soft skills. With regard to the soft skills cluster, as displayed in Figure 4, a classification of the key soft skills into four main areas, according to their nature, has been conducted.

To gain a simplified view on how the possible technological advancements may impact prospective skill requirements, Figure 4 pictures the Soft Skills Model for the Future of Work. The model illustrates both, the destruction effect (substitution) as well as the capitalization effect (complementation).

However, through the capitalization effect, new businesses, occupations and industries will be created, and thus the need for continuous improvement may be amplified as well. Through lifelong learning, inspired by enthusiasm and fueled by curiosity, the likelihood to be successful in the future labor market is likely to grow.

The complementation effect may highlight human-machine collaboration. First, with the Routinization Hypothesis, it was illustrated that the routine tasks of a job are most likely to be overtaken by machines. On the one hand, this means that workers are enabled by technology, leading to use their very human capacity that a machine cannot substitute.

Legend:

Scenario Capitalization Effect

Scenario Destruction Effect

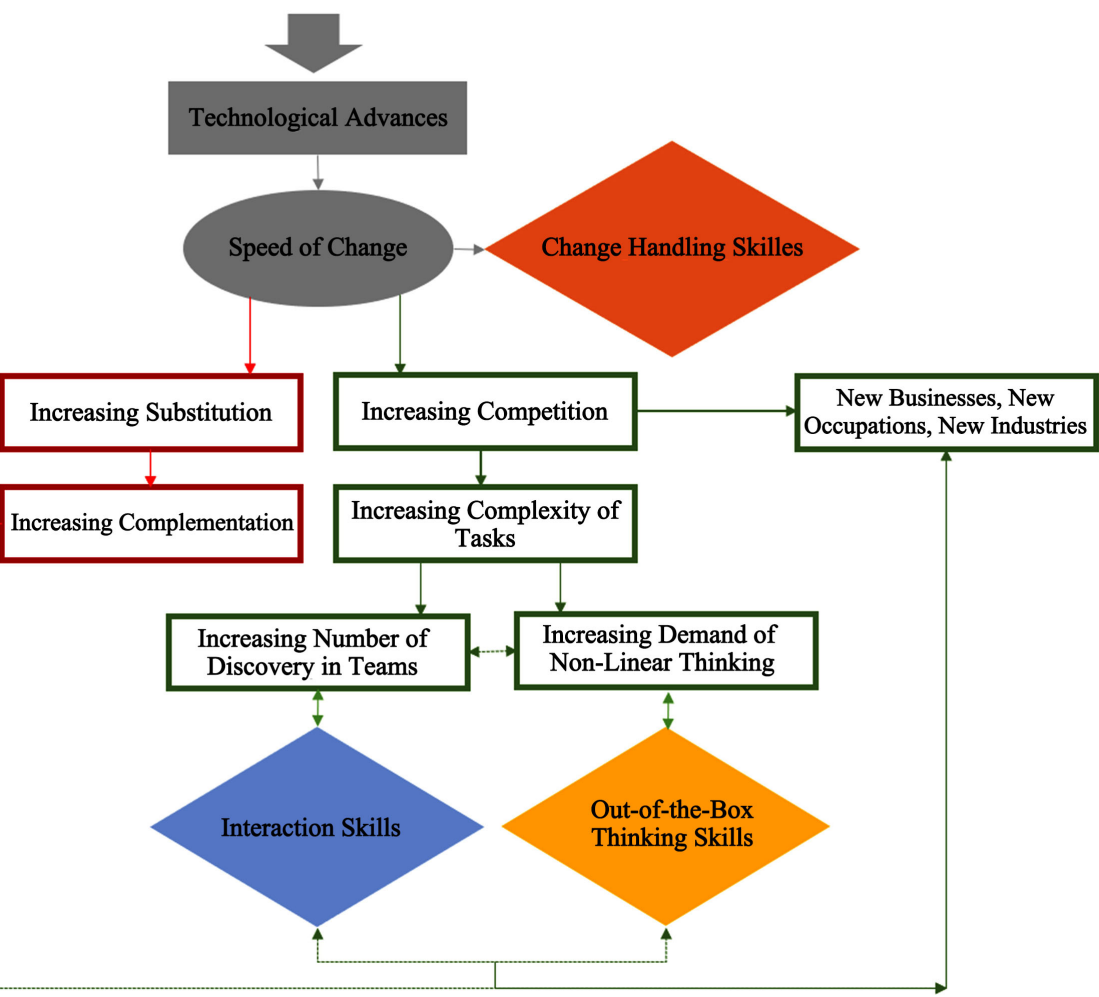

Figure 4. Soft skills model for the future of work. Source: Own creation based on both, the theoretical and empirical analysis. 
This, in turn, may imply that the demand for non-linear thinking may be highlighted. Linear thinking refers to the capacity of machines, which is suggested to be in favor to respect rule-based routine tasks, where machines can utilize their underlying set of data. Non-linear thinking, in contrast, refers to the out-of-the-box thinking capacity. Tasks that rely on non-binomial as well as out-of-the-box thinking, still do not lie within the framework of machines.

Even though with continuing technological advances, this frame is likely to be widening. Cognitive (thinking) skills, which refer to processing anything outside the given scheme, are considered the comparative advantage of humans over computers. Following this, the concept of out-of-the box thinking will shift alongside the technological advances.

Innovation capacity may further lead to new business opportunities, also in a case where the destruction effect will be predominantly present. The considerable complexity of tasks will lead to an increasing number of discoveries in interdisciplinary and multi-character teams, where specialized workers from all over the world collaborate within projects to tackle highly complex problems.

Regarding the two scenarios outlined in the aforementioned models, it is important to understand, that the two opposing effects of substitution and complementation may occur at the same time, depending on the stage of automation. In the first stage, complementation is stressed, whereas in the last stage, substitution is amplified. Especially in the middling stage of Augmented Intelligence, the two effects might overlap.

Lastly, the degree of which one effect tends to overrule the other one, plays a role for which skills may be amplified at what point. Thus, the Soft Skills Model for the Future of Work simplified the reality in this aspect.

Furthermore, in the last phase Autonomous Intelligence, where substitution is at its highest level, there might still be niches, where it would economically not make sense to automate certain tasks or where especially human traits are wished and thus being paid in form of a human premium.

\section{Conclusion}

Four main clusters of change handling skills, skills for continuous improvement, interaction skills as well as out-of-the-box thinking skills have been identified. Concerning the contribution of these soft skills cluster to success in the future of work, it has been revealed that depending on the prospective scenario, different soft skills may increase in importance.

The future might bring changes to the working world, including a higher pace and scale than in previous periods of economic transformation. However, technological advances should be considered as a tool allowing for a successful human-machine collaboration, where both the capabilities of technology and the human comparative advantage can be amplified. With such an interplay, the best possible outcome is likely to be achieved. However, to be part of such a cooperation between human and machine intelligence, employees need to acquire appropriate skills. 
Moreover, the importance of providing the workforce with the essential skills for the future of work cannot be overstated. Thus, education providers should pay more attention to soft skills within schooling, moving away from a focus on the technical hard skills towards an integration of both hard and soft skills. Such an integration would imply a transformation in education, moving from learning traditional fact- and rule-based knowledge to learning how to think critically and to be creative.

This shift would most certainly lead to improved innovation capacity. Furthermore, a shift away from an education system, where all students are taught the same, towards increased importance placed on the individuals' interests and capacities would further trigger the individual's enthusiasm, while at the same time allowing for more curiosity.

Next, a shift from learning as a basis to the acknowledgement of lifelong learning through self-development is proposed. Thus, skills from the four main soft skills clusters should be fostered independently throughout one's lifespan. It is the responsibility of each individual to be open for future changes and to continuously improve their own abilities through self-inspired enthusiasm and curiosity.

Additionally, the importance for interaction skills, owing to the increasing dependence on others, should be stronger embedded in the education system. The same holds for out-of-the-box thinking skills, which should be more often applied to find creative solutions and innovative pathways, leading into a prosperous future.

Nevertheless, the future of work might also be shaped by additional forces. Large-scale developments with regards to shifts in demographics or the ongoing globalization may strongly impact the future and define labor market conditions. This implies that changes in skill requirements for the prospective workforce may be impacted by additional factors that need to be taken in to account.

Finally, studies analyzing the development of soft skills more in-depth should be carried out by not only referring to schooling education but also by considering an individual's upbringing. As potential inequality might rise over time due to changes in skills and knowledge required for new types of tasks and jobs in an increasingly computerized working world, hence, up-skilling and re-skilling opportunities to provide individuals with the appropriate skills might be deemed necessary for the future.

\section{Conflicts of Interest}

The authors declare no conflicts of interest regarding the publication of this paper.

\section{References}

Acemoglu, D., \& Autor, D. (2011). Skills, Tasks and Technologies: Implications for Employment and Earnings. In Handbook of Labor Economics (Vol. 4, pp. 1043-1171). Amsterdam: Elsevier-North. https://doi.org/10.1016/S0169-7218(11)02410-5 
Andrews, J., \& Higson, H. (2008). Graduate Employability, "Soft Skills" versus "Hard Skills" Business Knowledge: A European Study. Higher Education in Europe, 33, 411-422. https://doi.org/10.1080/03797720802522627

Autor, D. (2015). Why Are There Still So Many Jobs? The History and Future of Workplace Automation. Journal of Economic Perspectives, 29, 3-30. https://doi.org/10.1257/jep.29.3.3

Autor, D. H. et al. (2003). The Skill Content of Recent Technological Change: An Empirical Exploration. The Quarterly Journal of Economics, 118, 1279-1333. https://doi.org/10.1162/003355303322552801

Autor, D. H., \& Dorn, D. (2013). The Growth of Low-Skill Service Jobs and the Polarization of the US Labor Market. American Economic Review, 103, 1553-1597. https://doi.org/10.1257/aer.103.5.1553

Brynjolfsson, E., \& McAfee, A. (2016). The Second Machine Age: Work, Progress, and Prosperity in a Time of Brilliant Technologies. New York: W.W. Norton \& Company.

Camerer, C. et al. (2005). Neuroeconomics: How Neuroscience Can Inform Economics. Journal of Economic Literature, 43, 9-64. https://doi.org/10.1257/0022051053737843

Colvin, G. (2015). Humans Are Underrated: What High Achievers Know That Brilliant Machines Never Will. Boston, MA: Harvard Business Review Press.

Cornell University, INSEAD, \& WIPO (2018). The Global Innovation Index 2018: Energizing the World with Innovation. Ithaca, Fontainebleau, and Geneva.

De Carvalho, M., \& Rabechini, R. (2015). Impact of Risk Management on Project Performance: The Importance of Soft Skills. International Journal of Production Research, 53, 321-340. https://doi.org/10.1080/00207543.2014.919423

Deloitte (2017). Soft Skills for Business Success. https://www2.deloitte.com/au/en/pages/economics/articles/soft-skills-business-success. html

Deming, D. J. (2017). The Growing Importance of Social Skills in the Labor Market. The Quarterly Journal of Economics, 132, 1593-1640. https://doi.org/10.3386/w21473

Eichhorst, W. (2017). Labor Market Institutions and the Future of Work: Good Jobs for AIR? IZA Policy Paper, No. 122.

Elias, P., \& Purcell, K. (2004). Is Mass Higher Education Working? Evidence from the Labour Market Experiences of Recent Graduates. National Institute Economic Review, 190, 60-67. https://doi.org/10.1177/002795010419000107

Frey, C., \& Osborne, M. (2013). The Future of Employment. How Susceptible Are Jobs to Computerization? Working Paper, Oxford: Oxford Martin. https://doi.org/10.1016/j.techfore.2016.08.019

Goos et al. (2009). Job Polarization in Europe. American Economic Review, 99, 58-63. https://doi.org/10.1257/aer.99.2.58

Goos et al. (2011). Explaining Job Polarization in Europe: The Roles of Technology, Globalization and Institutions. Geneva: International Labor Organisation. https://doi.org/10.2139/ssrn.1983952 http://www.ilo.org/wcmsp5/groups/public/---ed_emp/documents/genericdocument/w cms_158395.pdf

Katz, L. F., \& Murphy, K. M. (1992). Changes in Relative Wages, 1963-1987: Supply and Demand Factors. Quarterly Journal of Economics, 107, 35-78. https://doi.org/10.2307/2118323

Larsen, C. et al. (2016). Digital (R)evolution and Its Effects on Labour Opportunities and Challenges for Regional and Local Labour Market Monitoring. München: Rainer 
Hampp Verlag.

Matteson, M. et al. (2016). Soft Skills: A Phrase in Search of Meaning. Libraries and the Academy, 16, 71-88. https://doi.org/10.1353/pla.2016.0009

McLarty, R. (1998). Using Graduate Skills in Small and Medium Sized Enterprises. Ipswich: University College Suffolk Press.

Mokyr, J. et al. (2015). The History of Technological Anxiety and the Future of Economic Growth: Is This Time Different? Journal of Economic Perspectives, 29, 31-50. https://doi.org/10.1257/jep.29.3.31

Nabi, G. (2003). Graduate Employment and Underemployment: Opportunity for Skill Use and Career Experiences amongst Recent Business Graduates. Education and Training, 45, 371-383. https://doi.org/10.1108/00400910310499947

OECD (2016). Skills for a Digital World. https://www.oecd.org/els/emp/Skills-for-a-Digital-World.pdf

Ondobaka, S. et al. (2017). The Role of Interceptive Inference in Theory of Mind. Brain and Cognition, 112, 64-68. https://doi.org/10.1016/j.bandc.2015.08.002

PwC (2017). Workforce of the Future-The Competing Forces Shaping 2030. https://www.pwc.com/gx/en/services/people-organisation/workforce-of-the-future/wor kforce-of-the-future-the-competing-forces-shaping-2030-pwc.pdf

Rifkin, J. (1995). The End of Work: The Decline of the Global Labor Force and the Dawn of the Post-Market Era. New York: Putnam Publishing Group.

Schulz, B. (2008). The Importance of Soft Skills: Education beyond Academic Knowledge. Journal of Language and Communication, 2, 146-154.

Schwab, K. (2017). The Fourth Industrial Revolution (First U.S. Edition). New York: Crown Business.

Schwab, K., \& Davis, N. (2018). Shaping the Fourth Industrial Revolution. Geneva: World Economic Forum.

Syed, A. et al. (2010). The Importance of Soft Skills in Complex Projects. International Journal of Managing Projects in Business, 3, 387-340. https://doi.org/10.1108/17538371011056048

Tucker, M. et al. (2000). Training Tomorrow's Leaders: Enhancing the Emotional Intelligence of Business Graduates. Journal of Education for Business, 75, 331-338. https://doi.org/10.1080/08832320009599036

UNDP (2018). Human Development Indices and Indicators. 2018 Statistical Update.

Verick, S. (2018). The Puzzles and Contradictions of the Indian Labour Market: What Will the Future of Work Look Like? IZA Discussion Paper Series, No. 11376.

Wickramasinghe, V., \& Perera, L. (2010). Graduates', University Lecturers' and Employers' Perceptions towards Employability Skills. Education + Training, 52, 226-244. https://doi.org/10.1108/00400911011037355

Wilson, H. J., \& Daugherty, P. R. (2018). Human + Machine: Reimagining Work in the Age of AI. Boston, MA: Harvard Business Review Press.

Wilson, W. (1996). When Work Disappears. The World of the New Urban Poor. New York: Random House. https://doi.org/10.2307/2152085

WTO (2017). World Trade Report 2017. Trade, Technology and Jobs. https://www.wto.org/english/res_e/booksp_e/world_trade_report17_e.pdf

Zhang, Z. (2018). Artificial Neural Network. Multivariate Time Series Analysis in Climate and Environmental Research. Cham: Springer.

https://doi.org/10.1007/978-3-319-67340-0_1 


\section{Appendices}

\section{Appendix A: Overview of Primary Research Taken into Consideration}

\begin{tabular}{|c|c|c|}
\hline Expert & Position & Employer/Company \\
\hline Interviewee 1 & $\begin{array}{l}\text { Sales and Business } \\
\text { Development Lead Switzerland }\end{array}$ & $\begin{array}{l}\text { International company; consulting for chatbot } \\
\text { solutions }\end{array}$ \\
\hline Interviewee 2 & Head Delivery & $\begin{array}{l}\text { International company; specialized in executive } \\
\text { recruiting }\end{array}$ \\
\hline Interviewee 3 & $\begin{array}{l}\text { Director Enterprise } \\
\text { Solutions/Member of the } \\
\text { Executive Board }\end{array}$ & $\begin{array}{l}\text { MNE [multinational enterprise] in the technology } \\
\text { sector }\end{array}$ \\
\hline Interviewee 4 & Founder and CTO & $\begin{array}{l}\text { International company; providing brain } \\
\text { technology }\end{array}$ \\
\hline Interviewee 5 & $\begin{array}{l}\text { Advanced Data Analytics } \\
\text { and AI Specialist }\end{array}$ & MNE in the technology sector \\
\hline Interviewee 6 & Innovations Manager & MNE in the technology sector \\
\hline Interviewee 7 & Founder & $\begin{array}{l}\text { Swiss-based company; specialized in consulting } \\
\text { for innovation }\end{array}$ \\
\hline Interviewee 8 & $\mathrm{CEO}$ & $\begin{array}{l}\text { Swiss-based company; specialized in providing } \\
\text { mobile workplaces }\end{array}$ \\
\hline
\end{tabular}

Source: Own representation. Note: All interviews were conducted in April and May 2018.

\section{Appendix B: Substitution and Complementation According to the Stage of Automation}

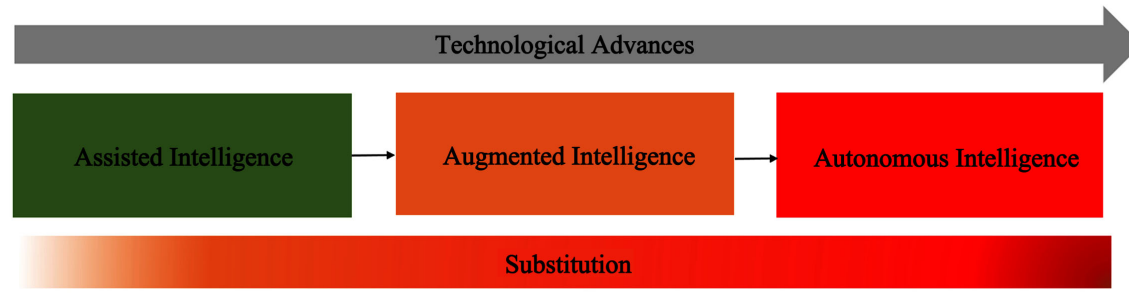

\section{Complementation}

Source: Own representation, three stages of automation according to PwC (2017). 